\title{
Characterisation of botanical starches as potential substitutes of agar in tissue culture media
}

\author{
Richard Madege ${ }^{1 \star}$, Emarold Mneney $^{2}$, Robert Misangu ${ }^{1}$ and Amon Maerere ${ }^{1}$ \\ ${ }^{1}$ Department of Crop Science and Production, Sokoine University of Agriculture (SUA), P. O. Box 3000, Morogoro, \\ Tanzania. \\ ${ }^{2}$ Cashew Biotechnology Unit (CBU), Mikocheni Agricultural Research Institute (MARI), P. O. Box 6226, Dar es Salaam, \\ Tanzania.
}

Received 31 October, 2014; Accepted 16 February, 2015

\begin{abstract}
Seven botanical starches; cassava, sweet potato, Irish potato, maize, rice, wheat and sorghum were characterized to determine physicochemical properties influencing gel formation for preparation of tissue culture media. Total starch, protein, fat, amylose content, swelling power and $\mathrm{pH}$ were determined using acid hydrolysis, enzymic and spectrophotmetric methods. Each type of starch was tested for ability to support in vitro plant growth and $0.8 \%$ agar $(w / v)$ was used as standard. Nodal explants cultures were initiated in Murashige and Skoog medium supplemented with $3 \%$ sucrose and $0.5 \mathrm{mg} / \mathrm{l}$ benzylaminopurine (BAP). After 21 days, number of leaves and nodes, plant height and fresh weight were determined for each treatment. Significant $(0.05)$ differences were observed between starch types in total starch, protein content and fats. Cassava had the highest starch content $(81.5 \%)$ and irish potato had the lowest $(29.3 \%)$. Highest protein content (12\%) was observed in maize starch and the lowest $(3.4 \%)$ in cassava. Fat content was highest $(6.2 \%)$ in wheat and lowest in cassava $(0.2 \%)$. Starch extract from rice had the highest amylose content $(31.12 \%)$ while the cassava starch extracts had the lowest $(20.75 \%)$. The starch extracted from wheat had the highest swelling power $(105.1 \%)$ while irish potato starch had the lowest (52.1\%). Sorghum starch had the lowest pH of 4.57 while the highest (6.92) was recorded in Irish potato starch. The growth of shoots in vitro on agar gelled media outperformed those of starch gelled media except for the number of leaves per shoot which cassava starch media recorded significantly the highest response $(P=0.05)$. Of all the starch gelled media, the best growth response was observed with cassava. Good performance was observed in starches with high starch content, low amylose content and high swelling powers.
\end{abstract}

Key words: Starch, agar, gelling agent, in vitro plant growth.

\section{INTRODUCTION}

Agar, an extract of red algae sea weeds is a natural polysaccharide made up of agarose and agaropectin (Villanueva et al., 2010). It is widely used in food and non food industries including biotechnologies like tissue culture (TC). Its wide application is due to its gelling ability and gel characteristics. The gel characteristics

*Corresponding author. E-mail: richmadege@yahoo.co.uk. Tel: +255 765288222.

Author(s) agree that this article remain permanently open access under the terms of the Creative Commons Attribution License 4.0 International License 
include ability to form a gel at around $30^{\circ} \mathrm{C}$ that melts at about $100^{\circ} \mathrm{C}$ and re-solidifies at about $45^{\circ} \mathrm{C}$ (Gangopadhyay et al., 2009; Marinho-Soriano and Bourret, 2005). It is highly preferred in preparation of solid TC medium because the gel has high clarity and stable gel strength. Also, it does not react with components of the medium and it is not digested by plant enzymes (Vaz-Pires et al., 2008). In addition, agar has high purity levels and high resistance to alteration during culture (Gangopadhyay et al., 2009). Due to these favorable physical-chemical attributes, agar has been a gelling agent of choice of majority TC systems as it assures adequate support and translocation of water and mineral nutrients to explants. However, although several reports show that agar is non toxic with highest purity level, others have reported presence of impurities and differences in type and quality between brands which have been associated with adverse effects like inhibition of growth, hyperhydricity, necrosis and cytotoxic effects (George et al., 2008; Ivanova and Van Staden, 2011; Ozel et al., 2008). For many decades, tissue culture was confined only in research laboratories until it started to be used in commercial mass propagation. From that point the concept of cost effectiveness in TC became important. Reports show that the total cost of micropropagation is influenced by a number of factors including chemical media. However there are some differences in opinion whether media costs really contribute a significant portion of the total cost (Goel et al., 2007) and others are convinced that the refined agar powder generally used in plant tissue culture media is a costly commodity (Escobar et al., 2006; George et al., 2007). This is supported by a reports that $30 \%$ of the total cost of production is due to chemical media of which more than $70 \%$ is the cost of gelling agent (Prakash, 1993). Apart from being expensive, also overreliance on agar could result to overexploitation from the natural ecosystem. Therefore research to investigate the potential substitute has been a justifiable agenda for many years. Several botanical alternatives have been proposed since 1980s. These include those of Henderson and Kinnersley (1988) who first demonstrated that growth and differentiation of plant cell cultures was increased when media were gelled with corn starch instead of agar. Results of other workers show that starch based media promoted callusing although growth of plants in vitro was improved when starch was mixed with agar (Babbar et al., 2005; Babbar and Jain, 2006).

Several workers who have reported the use of starch as gelling agents, show that, the in vitro plant growth was higher in starch gelled medium than the agar gelled medium (Jain et al., 2005). However others record growth lower than the agar based media and some improvement is observed when starch is mixed with agar at certain ratios (Kuria et al., 2008; Mohamed et al., 2010). It has been established that the different results could be due to differences in physical and chemical nature of the used starch (George et al., 2008). Starch, is made up of two major polymers: amylose and amylopectin which are structurally different. The former is linear while the later is highly branched and each structure plays a critical role in the ultimate functionality of starch. The amylose/ amylopectin ratio which is both environmentally and genetically manipulated determines the functional properties such as swelling power, water biding capacity, gel strength, shear resistance, gelatinization, textures, solubility, tackiness, gel stability, cold swelling, viscosity and retro gradation (Mweta et al., 2008). Colour and clarity are also important properties of starch gels in regeneration and management of tissue cultures. From the review, it is clearly noted that although, the physicalchemical characteristics of starchy gelling agents are important, reports on relationship of these properties with performance of plants in vitro are lacking. This paper therefore reports the physical and chemical characteristics of seven botanical starches and their ability to support growth of in vitro plant.

\section{MATERIALS AND METHODS}

Starch was extracted from maize (Zea Mays L; var Stuka) and wheat (Triticum aestivum L; Var Riziki) which were obtained from Agricultural Research Institute (ARI)-Seliani, Arusha, Tanzania. Sorghum (Sorghum bicolour L; Var Macia) and rice (Oriza sativa L;Var TXD 305) were obtained from ARI-llonga and Cholima research station respectively both in Morogoro region, Tanzania. Fresh tuberous roots of cassava (Manihot esculanta Crants; Var Kiroba), Irish Potato (Solanum tuberosome L; Var CAP) and sweet potato (Ipomoea batatas L) were bought from local market. Sweet potato (var. Ukerewe) which was used as test plant was obtained from germplasm collection at ARI-Kibaha, Coast region Tanzania.

\section{Starch isolation}

Standard alkali methods described in the literature were used for the extraction of starch from sorghum and maize grains (Beta and Corke, 2001; Ji et al., 2004). One kilogram of both maize and sorghum (var Macia), were air screened and washed using tape water to remove contaminants before the maize sample was taken to a grinding mill for course grinding to remove the pericarp and germ. The samples were then rewashed and maize steeped in $1 \%$ $\mathrm{NaOH}$ and sorghum in $0.25 \% \mathrm{NaOH}(\mathrm{w} / \mathrm{v})$ solution at $45^{\circ} \mathrm{C}$ water bath for $24 \mathrm{~h}$ to loosen the endosperm. The steeped grains were washed using distilled water and wet ground $(1: 1 \mathrm{w} / \mathrm{v})$ in commercial blender. The slurry was filtered through triple cheese muslin cloth and the remaining materials were re-washed, re-filtered and the remaining grains subjected to repeated grinding and filtration. The filtrate was left to sediment at room temperature for 8 $\mathrm{h}$ before the supernatant was drained off. The remaining sediments were oven dried at $30^{\circ} \mathrm{C}$ for $24 \mathrm{~h}$. The dried starch in form of pellets was subjected to a laboratory hummer mill (3000 rpm) to obtain a fine powder.

Rice and wheat starches were extracted using methods described in the literature (Lumdubwong and Seib, 2000) with some modification. One kilogram of rice and wheat grains were air screened and washed to remove foreign materials before they were air dried. The samples were ground into flour using hummer mill (3500 rpm) before the flour was manually mixed with water in doses 
to a $1: 1(w / v)$ flour to water ratio forming coherent dough. The dough was then incubated at room temperature for $4 \mathrm{~h}$ before the dough was knead under distilled water to release the starch into water. Ten (10) washings were done to ensure starch is removed from the dough matrix remaining with gluten protein. The slurry was washed through filtering through a series of sieves $(500,200,120$ and $75 \mu \mathrm{m}$ ). All other operations regarding the filtrate to a final starch powder are as described in the method for maize and sorghum.

Extraction from cassava, sweet potato and potato was carried out using a modified method based on standard procedures (Benesi, 2005; Riley et al., 2006). Two kilograms of each of the fresh tubers and roots were washed, peeled and grated into a pulp. The pulp (mixture) was stirred for 2 min and filtered using a triple cheese (muslin) cloth. The filtrate was allowed to stand to facilitate starch sedimentation for $8 \mathrm{~h}$ before the supernatant was decanted and discarded while the remaining sediments were air dried to obtain the starch powder.

\section{Determination of physicochemical properties of starch extracts}

\section{Starch purity}

Starch content of triplicate samples of each of the seven extracts was determined according to Bhagya et al. (2006). A total of 100 $\mathrm{mg}$ of starch extract was defatted by boiling in $30 \mathrm{ml}$ of $80 \%$ ethanol for $10 \mathrm{~min}$ and the residue collected was dried at $70^{\circ} \mathrm{C}$ for $4 \mathrm{~h}$. To the residue, $10 \mathrm{ml}$ of $52 \% \mathrm{HClO}_{4}$ was added to digest the starch for $15 \mathrm{~min}$ at $28^{\circ} \mathrm{C}$ of the water bath and made up to $25 \mathrm{ml}$ with distilled water after which the mixture was filtered through Whatman No.1. Dubois method (Dubois et al., 1956) was employed to determine the total sugars.

About $20 \mu \mathrm{l}$ of the filtrate was made up to $1 \mathrm{ml}$ with distilled water then $1 \mathrm{ml}$ of $5 \%$ phenol followed by $5 \mathrm{ml} 36 \mathrm{~N} \mathrm{H}_{2} \mathrm{SO}_{4}$ were added. Pure glucose (Sigma) $(20-100 \mu \mathrm{m})$ was taken as standard from which a standard curve was established. Absorbance of the solution was read at $490 \mathrm{~nm}$ using a spectrophotometer (Altrospec 2000 by Pharmacia biotech). The amount of sugar contained in each sample of starch extract was calculated from the standard curve and the respective starch content was calculated as total sugar multiplied by 0.9 .

\section{Amylose content}

A triplicate sample which weighed $100 \mathrm{mg}$ of starch was defatted according to the standard AOAC methods (Riley et al., 2006) with modification. About $1 \mathrm{ml}$ of absolute (99.9\%) ethanol was added to the sample followed by votexing for $1 \mathrm{~min}$ before leaving the mixture to settle for 30 min after which ethanol was decanted off. To this mixture, $9.0 \mathrm{ml}$ of $1 \mathrm{M} \mathrm{NaCl}$ was added and the volume was made up to $100 \mathrm{ml}$ with distilled water. From this mixture, $5.0 \mathrm{ml}$ of an aliquot was transferred to a volumetric flask containing $25.0 \mathrm{ml}$ of water. To this volume $19.0 \mathrm{ml}$ of $1 \mathrm{M}$ acetic acid and $1.0 \mathrm{ml}$ of $0.2 \%$ lodine solution were added making the volume up to $50 \mathrm{ml}$ with distilled water.

Absorbance of the resulting solution at $620 \mathrm{~nm}$ for amylose was read using a spectrophotometer (Altrospec 2000 by Pharmacia biotech). Standard amylose in varying concentrations was used to construct a standard curve from which the concentrations of amylose in different samples of starch were calculated based on Lambert and Beer's equation represented as; $A=e b c$, where $A$ is absorbance, e is the molar absorptivity with units of $\mathrm{L} \mathrm{mol}^{-1} \mathrm{~cm}^{-1,} \mathrm{~b}$ is the path length of the sample and $c$ is the concentration of the compound in solution, expressed in mol L-1 (Nelson et al., 2008).

\section{Swelling powers}

The swelling power of the starch granules was determined using previously described methods ( $\mathrm{Li}$ and Yeh, 2001; Leach et al., 1959) with little modification. Firstly the centrifuge tubes were weighed (W1). Secondly, a triplicate sample weighing $0.1 \mathrm{~g}$ of starch (W2) from the seven sources were put in pre-weighed tubes and incubated in water bath at $60^{\circ} \mathrm{C}$ and another same amount at $30^{\circ} \mathrm{C}$ both for $30 \mathrm{~min}$. After incubation, the samples were centrifuged at $7000 \mathrm{rpm}$ for $20 \mathrm{~min}$ followed by decanting the supernatant before weighing the wet sample (W3). Swelling power was determined as the percentage change in the weight of samples of starch calculated using the formula:

Swelling power $=\frac{W 3-W 1+W 2}{W 2} \times 100$

\section{Protein content}

Protein was estimated using the Bradford method (Kruger, 2009). The standard procedures were used to prepare a Bradford reagent and kept was in brown glass bottle. Starch samples each weighing $5 \mathrm{~g}$ in triplicate were mixed with $10 \mathrm{ml}$ of distilled water from which $0.5 \mathrm{ml}$ was drawn to be mixed with $0.5 \mathrm{ml}$ of de-lonized water followed by adding $5 \mathrm{ml}$ of Bradford reagent. This mixture was well mixed by vortexing for $1 \mathrm{~min}$ and thereafter left to settle for $5 \mathrm{~min}$. After settling, absorbance at $595 \mathrm{~nm}$ was read from spectrophotometer (Ultraspec 2000 by Pharmacia biotech). The protein concentration was then estimated from a standard curve, which was prepared using a standard protein (Bovine serum albumin).

\section{Crude fat content}

Crude fat content of the samples was estimated using Soxhlet apparatus (Kruger, 2009). In this method, $2 \mathrm{~g}$ of starch (W2) in triplicate samples were put in a pre-weighed (W1) filter paper (Whatman No 1) after which they were taken into the soxhlet system for lipid extraction using chloroform and hexane mixed in $1: 1$ ratio. The remaining fat free sample was dried and re-weighed (W3) then fat content was calculated as a percentage change from the formula:

$$
\text { Crude Fat }=\frac{W 1+W 2-W 3}{W 2} \times 100
$$

\section{Starch $\mathrm{pH}$}

Starch $\mathrm{pH}$ was determined based on method described in (Agudelo et al., 2014). A triplicate sample weighing $5.0 \mathrm{~g}$ was homogenised using $25.0 \mathrm{ml}$ distilled water for $60 \mathrm{~s}$. The starch was then allowed to settle for $15 \mathrm{~min}$. $\mathrm{pH}$ of the water phase was measured using $\mathrm{pH}$ meter glass electrode.

\section{Gel strength, colour and clarity}

A total of 63 formulations of tissue culture (TC) media gelled by seven types of starch each with six concentrations: $6,9,12,15,18$ and $21 \%(\mathrm{w} / \mathrm{v})$ were prepared using standard procedures for media preparations. Three people experienced in preparing TC medium were assigned to score each treatment for the degree of gel 
Table 1. Starch characteristics showing the influence of different botanical sources.

\begin{tabular}{|c|c|c|c|c|c|c|c|}
\hline \multirow{2}{*}{$\begin{array}{l}\text { Starch } \\
\text { source }\end{array}$} & \multirow{2}{*}{ Starch (\%) } & \multirow{2}{*}{ Protein (\%) } & \multirow{2}{*}{ Fat (\%) } & \multirow{2}{*}{$\begin{array}{c}\text { Amylose } \\
(\%)\end{array}$} & \multicolumn{2}{|c|}{ Swelling power } & \multirow{2}{*}{$\mathrm{pH}$} \\
\hline & & & & & at $30^{\circ} \mathrm{C}$ & at $60^{\circ} \mathrm{C}$ & \\
\hline Cassava & $81.49 \pm 0.79^{d}$ & $3.60 \pm 0.67^{\mathrm{a}}$ & $0.26 \pm 0.16^{a}$ & $20.75 \pm 0.23^{a}$ & $43.08 \pm 5.38^{\mathrm{bcd}}$ & $118.11 \pm 5.01^{d}$ & $5.92 \pm 0.04^{d}$ \\
\hline Sweet potato & $77.51 \pm 1.85^{\mathrm{cd}}$ & $9.90 \pm 0.14^{\mathrm{cd}}$ & $1.94 \pm 0.05^{b}$ & $21.82 \pm 0.47^{b}$ & $37.50 \pm 1.90^{\mathrm{bc}}$ & $83.95 \pm 3.99^{c}$ & $6.22 \pm 0.07^{\mathrm{e}}$ \\
\hline Irish potato & $29.32 \pm 3.89^{\mathrm{a}}$ & $8.23 \pm 0.31^{\mathrm{bc}}$ & $4.78 \pm 0.49^{c}$ & $23.42 \pm 0.33^{\mathrm{c}}$ & $27.59 \pm 1.66^{a}$ & $73.26 \pm 7.92^{\mathrm{bc}}$ & $6.90 \pm 0.06^{f}$ \\
\hline Rice & $75.63 \pm 3.58^{\mathrm{cd}}$ & $22.86 \pm 1.60^{\mathrm{e}}$ & $0.65 \pm 0.03^{\mathrm{a}}$ & $31.12 \pm 0.42^{d}$ & $50.59 \pm 0.77^{d}$ & $74.13 \pm 2.29^{c}$ & $4.72 \pm 0.04^{\mathrm{ab}}$ \\
\hline Wheat & $72.35 \pm 1.07^{\mathrm{bcd}}$ & $10.75 \pm 1.47^{\text {cd }}$ & $6.54 \pm 0.22^{d}$ & $24.09 \pm 0.28^{c}$ & $34.76 \pm 1.24^{\mathrm{ab}}$ & $50.48 \pm 4.92^{\mathrm{a}}$ & $5.42 \pm 0.05^{\mathrm{c}}$ \\
\hline Sorghum & $67.35 \pm 2.21^{\mathrm{bc}}$ & $6.36 \pm 0.45^{\mathrm{b}}$ & $1.83 \pm 0.09^{b}$ & $30.10 \pm 0.40^{d}$ & $44.85 \pm 1.55^{\mathrm{cd}}$ & $59.96 \pm 2.13^{\mathrm{ab}}$ & $4.57 \pm 0.20^{\mathrm{a}}$ \\
\hline Maize & $62.81 \pm 7.50^{\mathrm{b}}$ & $12.08 \pm 0.06^{d}$ & $0.46 \pm 0.18^{a}$ & $23.73 \pm 0.04^{c}$ & $29.69 \pm 4.47^{e}$ & $52.53 \pm 0.84^{\mathrm{a}}$ & $4.93 \pm .01^{\mathrm{b}}$ \\
\hline
\end{tabular}

Means followed by the same letter within the column are not significantly different at $P \leq 0.05$.

strength based on modified 7 point scale (0-1=liquid, 2-3=semi liquid, 4-5= semi solid, 6-7 = solid) (Lee and Chung, 1989). A colour of starch powder was determined using a colour checker (Park et al., 2006) in a range scores of 1-3 = light medium gray, $4-8=$ medium gray, 9-12 = light dark gray and $13-16=$ dark gray. The gel clarity was scored using a four point scale $(1=$ Transparent, $2=$ Semi transparent, $3=$ Semi opaque and $4=$ Opaque)(Novelo-Cen and Betancur-Ancona, 2005).

\section{Assessment of the ability of starch based media to support in vitro plant growth}

Sweet potato cultures were established in tissue culture media which were solidified by starches extracted from wheat, rice, sorghum, maize, cassava, sweet potato, Irish potato and $0.8 \%$ agar $(w / v)$ was used as standard. Surface sterilized nodal explants cultures were initiated in Murashige and Skoog (MS) medium (Murashige and Skoog, 1962) supplemented with 3\% sucrose and $0.5 \mathrm{mg} / \mathrm{l}$ benzylaminopurine (BAP). After 21 days, number of leaves and nodes, internode length, plant height and fresh weight were determined for each explant.

\section{Data collection and analysis}

Variance analysis was calculated based on the statistical models $Y_{i j}$ $=\mu+A_{i}+\varepsilon_{i j}$; where, $Y_{i j}$ is the $j^{\text {th }}$ observation in treatment $i ., \mu$ is the overall mean, $A_{i}$ is the $i^{\text {th }}$ treatment effect, (type of starch), and $\varepsilon_{i j}$ is random error component using a software; GENSTAT discovery edition 3 (Payne, 2009); mean separation tests were performed using least square differences (LSD).

\section{RESULTS}

\section{Chemical characteristics of starch extracts}

Analysis of Variance in Table 1 shows significantly $(p \leq$ 0.05 ) different properties of starch extracts from different botanical sources. The extracts contained none starch biomolecules like protein and fat in different $(p=0.05)$ proportions. Starch purity $(81.49 \%)$ of cassava was almost three times higher than the extracts from Irish potato. Highest protein $(22.86 \%)$ was observed in rice starch while wheat had the highest $(6.54 \%)$ fat content (Table 1).
The seven starch extracts had significantly different $(P$ $\leq 0.05$ ) amounts of amylase content. The starch extract from rice was found to have the highest (31.12\%) amylose content while the cassava starch extracts had the lowest $(20.75 \%)$ (Table 1$)$.

The swelling power of starch varied $(p \leq 0.05)$ with its botanical source (Table 1). Also the swelling power of each starched type increased with increasing incubation temperature except the starch from maize. Significantly $(p=0.05)$ highest increase was observed in wheat starch where a temperature change from 30 to $60^{\circ} \mathrm{C}$ increased the swelling by $140.72 \%$ while in the same change of temperature, the swelling power of sorghum increased by only $15.31 \%$.

The $\mathrm{pH}$ of different starch extracts varied $(\mathrm{p} \leq 0.05)$ with the botanical sources (Table 1). Sorghum starch had the lowest $\mathrm{pH}$ of 4.57 while the highest (6.92) was recorded in Irish potato starch. Generally the $\mathrm{pH}$ of cereal starch extracts was lower than those of root and tuber starches.

\section{Gel characteristics of starch based tissue culture media in different concentrations}

\section{Gel strength}

The summary of results for gel strength scores are presented in Figure 1. The gel strength of TC media which were solidified by all starch types increased with increasing concentration. Maize starch formed a semisolid gel at the lowest $(9 \% \mathrm{w} / \mathrm{v})$ concentration while rice starch attained the same score at the highest $(18 \% \mathrm{w} / \mathrm{v})$.

\section{Gel colour}

The media which were solidified using the different botanical starches consistently changed colours from semi transparent to opaque. Root and tuber starch gels attained an dark gray from a concentration of $18 \%$ while the cereal starch gels were medium gray except sorghum 


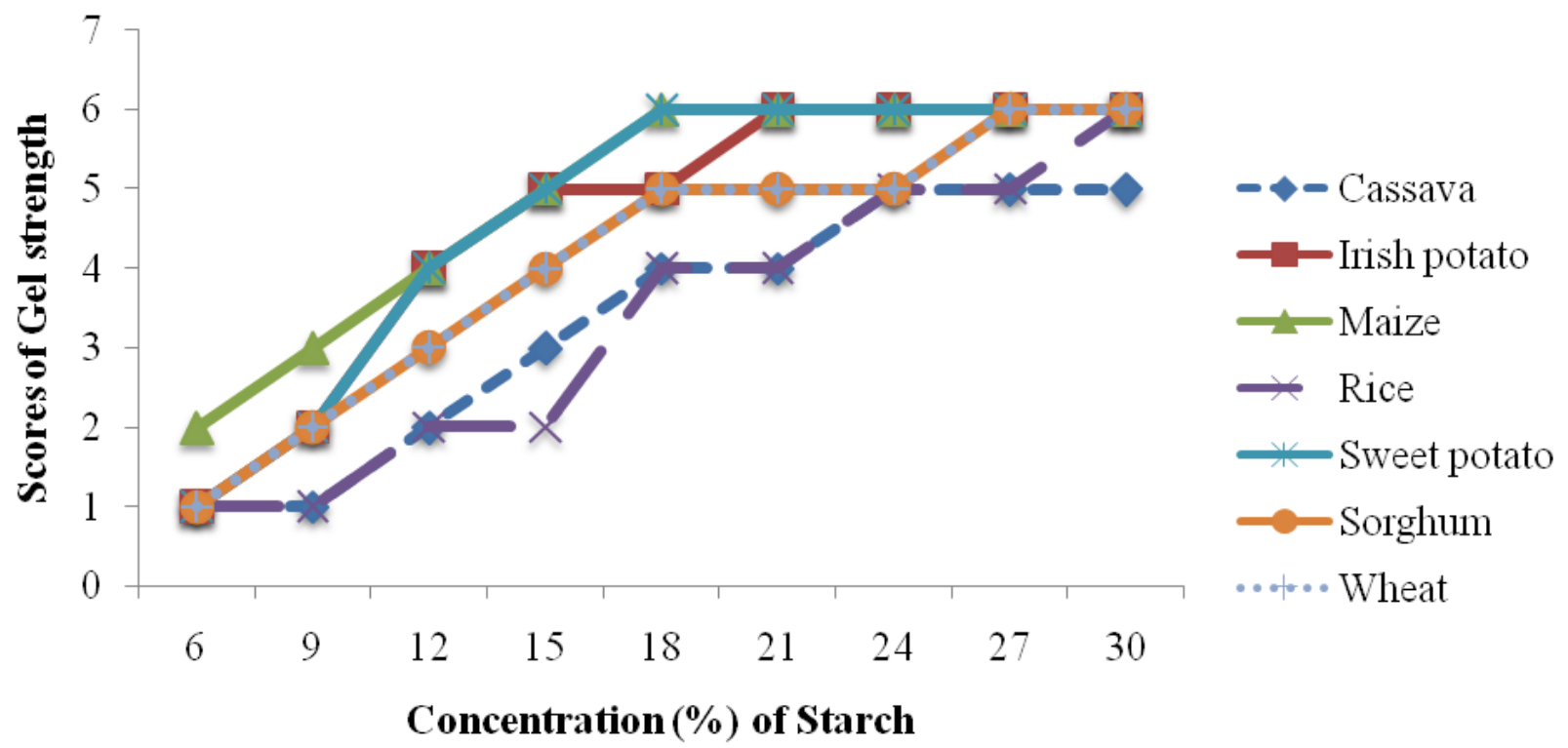

Figure 1. Effect of botanical source on gel strength of starch based tissue culture (TC) medium.

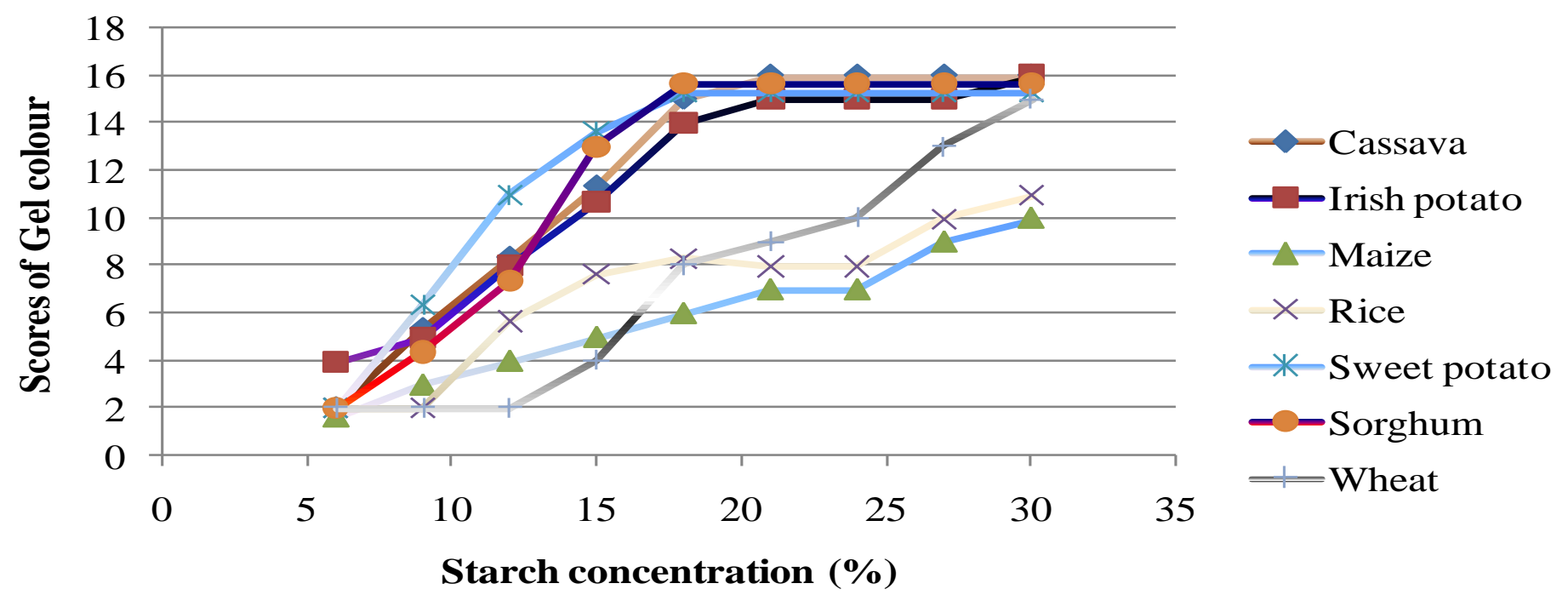

Figure 2. Effect of botanical source and concentration on colour of gels for starch based tissue culture (TC) medium.

starch gels which had results similar to those of root and tubers (Figure 2). Of the three root and tuber starch based medium, cassava produced medium with lowest scores of both gel colour.

\section{Gel clarity}

Figure 2 shows lost clarity with increasing concentration after $15 \mathrm{~min}$ autoclaving at $121^{\circ} \mathrm{C}$. Clarity and colour scores of TC medium based on roots and tuber starches were lower than those from cereal sources (Figure 3).
Influence of types of botanical sources of starches on in vitro plant development

The results presented in Figure 4 show that the influence of starch based TC medium solidified starches of cassava, sweet potato and Irish potato on foliar (Figure $4 \mathrm{~A}$ ) and nodal (Figure 4B) development were not significantly different $(p=0.05)$ from the control. Nodal and foliar development of explants grown in TC medium solidified by starches from cereals (maize, rice, wheat and sorghum) were significantly $(P \leq 0.05)$ lower than for the control (Agar based media) as well as TC media 


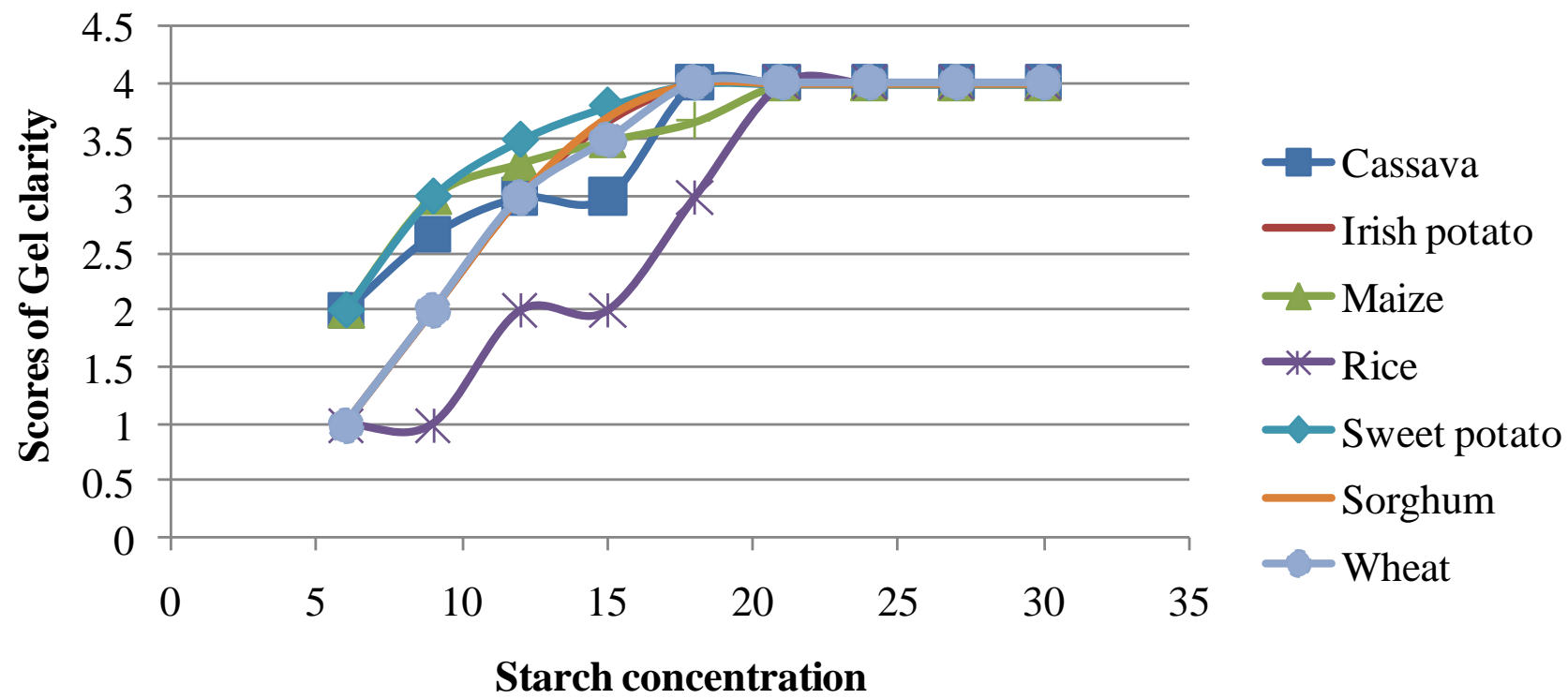

Figure 3. Influence of botanical sources of starch on clarity of gels for starch based tissue culture (TC) media.

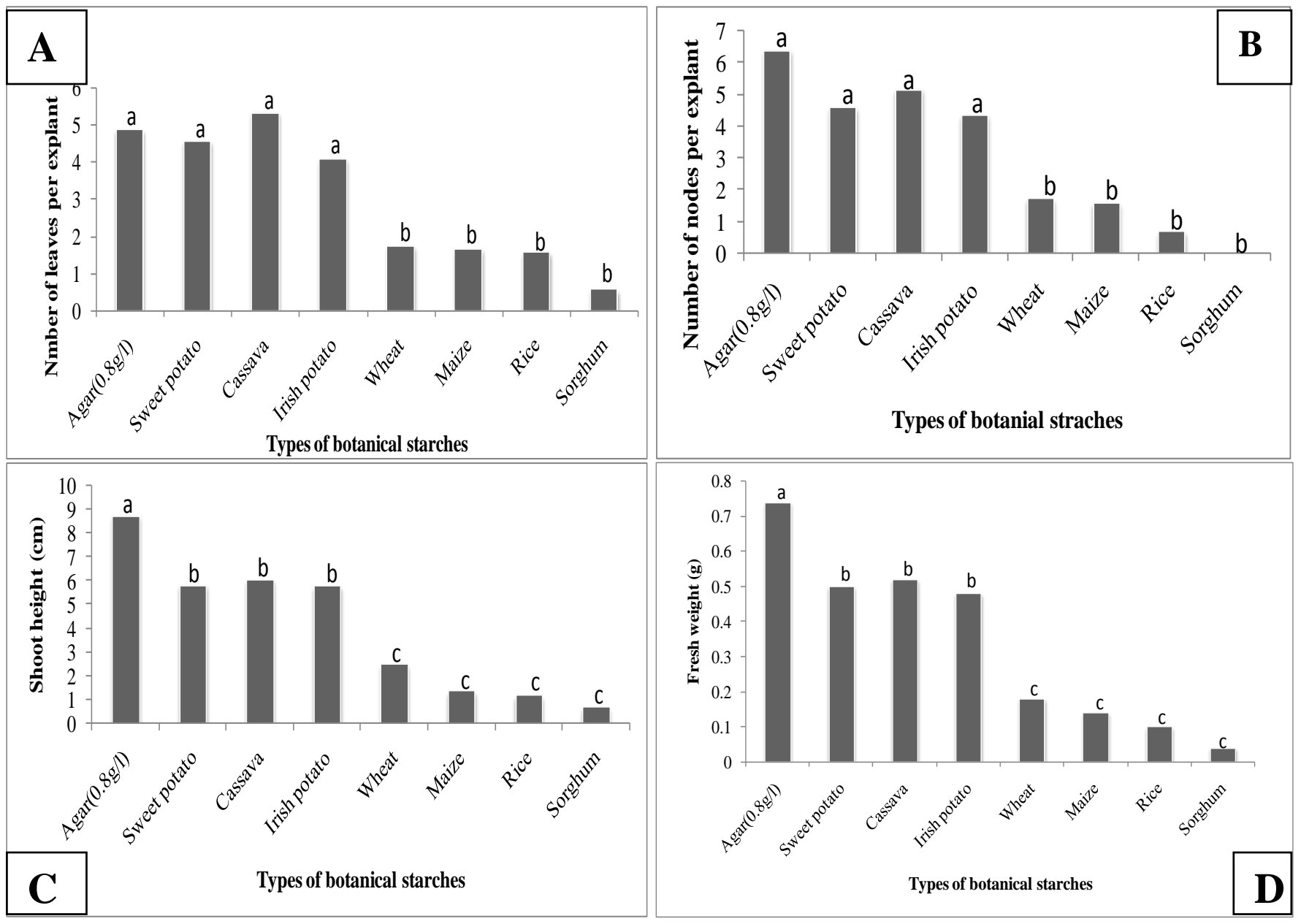

Figure 4. The potential of different botanical sources as alternative gelling agent of tissue culture (TC) media for plant micropropagation (means which are represented by bars headed with same letters are not significantly different $(p=0.05)$. 


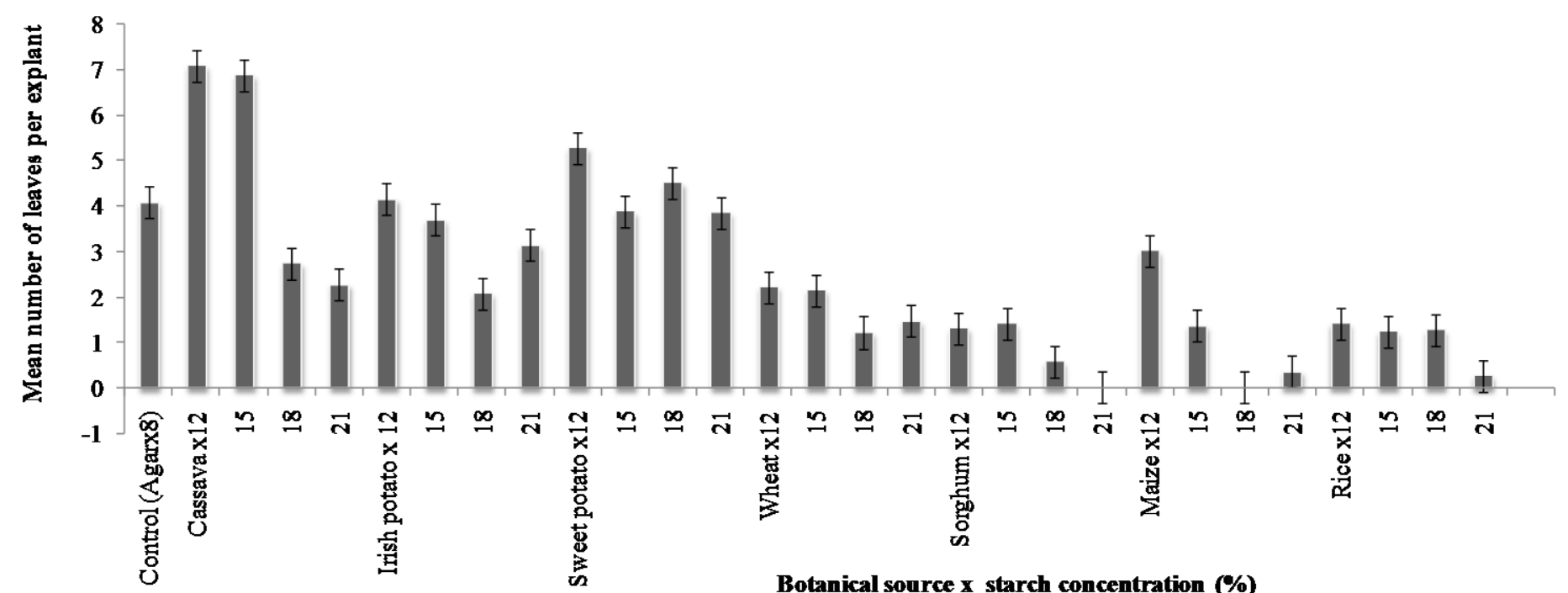

Figure 5. the influence of botanical source of starch and concentration (\%) on in vitro development of leaves in vitro; Means represented with none overlapping standard error bars are significantly different $(p=0.05)$.

solidified by starch extracts of cassava, sweet potato and Irish potato.

Significant differences $(p=0.05)$ between types of TC medium were observed in terms of height (Figure $4 C$ ) and fresh weight (Figure 4D). Height (Figure 4C) and fresh weight (Figure 4D) of plantlets growing in the control (Agar based TC medium) were significantly $(p=$ $0.05)$ higher than all starches.

Height and fresh weight parameters of explants growth in TC medium gelled by cassava, sweet potato and Irish potato were not statistically different $(p=0.05)$ but they significantly outperformed those grown in cereal based starches.

\section{The influence of botanical source and concentration of starch on in vitro growth of sweet potato}

\section{Development of photosynthetic apparatus}

The result in Figure 5 shows significantly different $(p=$ 0.05 ) numbers of leaves produced per explants in TC media solidified by starch of different botanical sources and concentration (Figure 5). Cassava starch at concentrations of $12,15 \%$ and sweet potato at $12 \%$ outperformed the control by more than a unit (Figure 5). The number of leaves per shoot recorded in TC media gelled by $12 \%(\mathrm{w} / \mathrm{v})$ Irish potato starch (4.58) was not statistically different $(p=0.05)$ from the performance of the control on the same. Exceptionally, the number of leaves per shoot in maize starch based TC medium at $12 \%$ concentration was significantly higher than the rest of cereal starches though lower than root and tuber starches as well as the agar based TC medium (Figure $5)$.

\section{Development of propagation units}

Number of axillury buds produced by explants in TC medium solidified by starch of different botanical sources and concentrations were significantly different $(p=0.05)$ (Figure 6). The TC media gelled by cassava starch at the concentration of $15 \%$ produced shoots whose number of axillary buds was higher (8.14) than those of the control (5.87) but also was the highest of all starch based media (Figure 6).

The number of axillury buds per shoot recorded in the control media was statistically the same as those produced in TC media which were solidified by Irish potato and sweet potato starches both at the concentration of $12 \%(\mathrm{w} / \mathrm{v})$. The response observed in all TC media which were solidified by starch from cereal extracts ranged from 0 to 4.93 which were significantly ( $p$ $=0.05$ ) lower than the control (Figure 6 ). The number of axillury buds was negatively affected by increasing starch concentration beyond $18 \%$

\section{Growth performance of in vitro plantlets}

Figure 7 shows significant different $(p=0.05)$ heights of in vitro plantlets in TC media which were solidified by starches from different botanical sources and applied at different concentrations. Plant height in cassava starch gelled media ( $15 \%$ cassava) did not vary $(p=0.05)$ from the control but outperformed all other treatments. Within each treatment, lowest plant height was observed at concentration higher than $18 \%$ except sweet potato starch gelled media (Figure 7).

Different types of gelling agents applied at different concentrations had different effect on fresh weight of the 


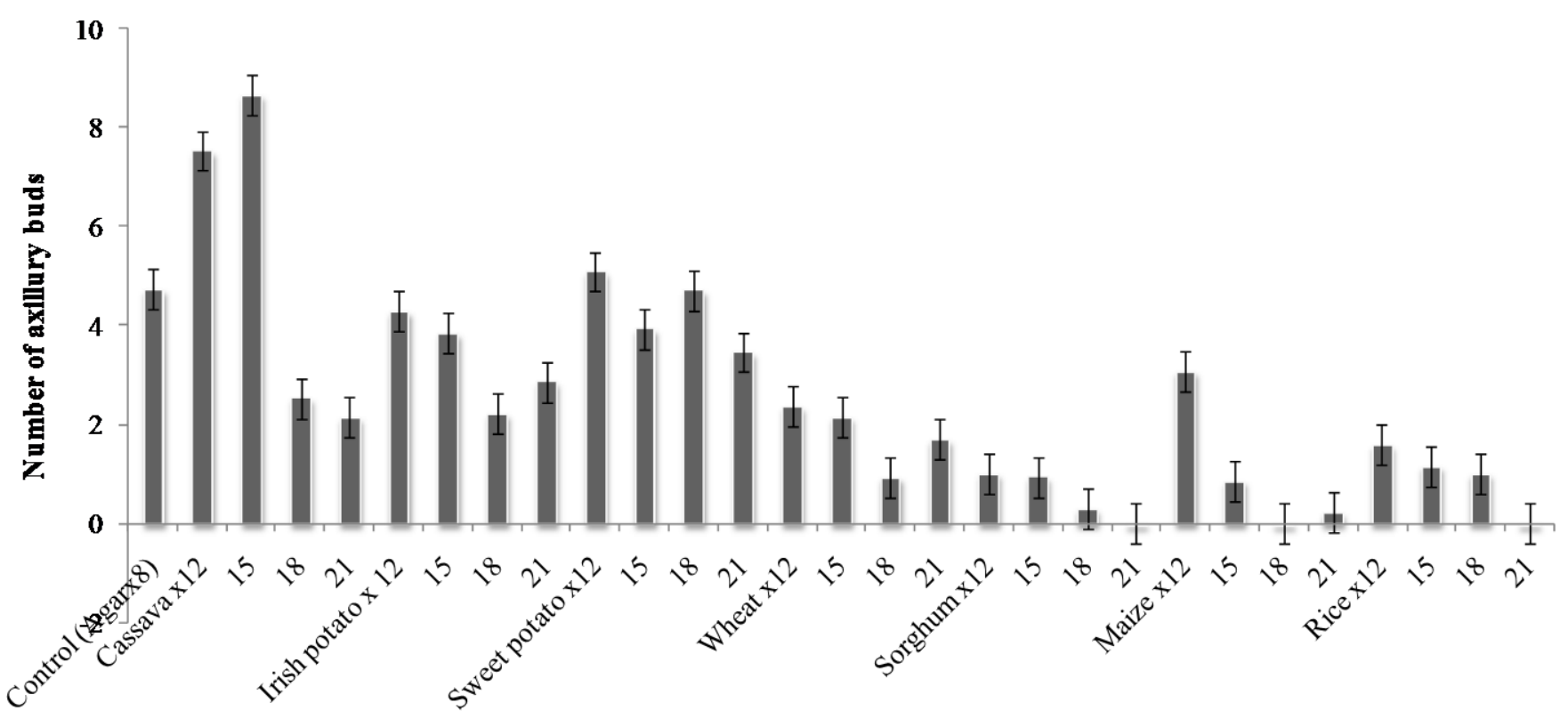

Botanical source $x$ starch concentration (\%)

Figure 6. the influence of botanical source of starch and concentration on in vitro production of budded propagules; Means represented with none overlapping standard error bars are significantly different $(p=0.05)$.

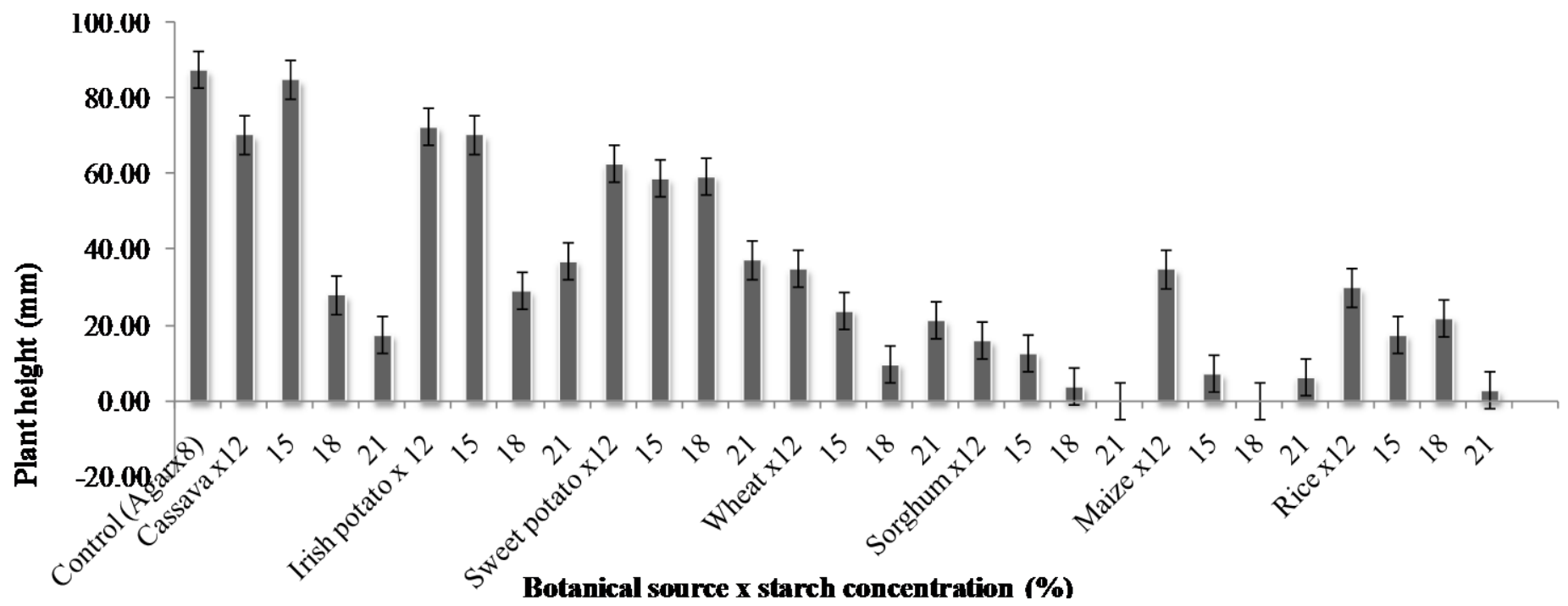

Figure 7. Influence of botanical source of starch and concentration on height of in vitro plantlets; Means represented with none overlapping standard error bars are significantly different $(p=0.05)$.

in vitro shoots $(\mathrm{P}=0.05)$. Plantlets grown in $12 \%$ cassava starch accumulated the highest biomass followed by $12 \%$ Irish potato and sweet potato starches. Fresh weight attained in $15 \%$ cassava, Irish potato and sweet potato did not vary $(p=0.05)$ from the control. The fresh weight of shoots grown on TC media solidified by root/tuber starches ranged from 0.16 to $0.8 \mathrm{~g}$ which was higher than the range of $0-0.35$ for shoots produced on cereal starch (Figure 8).

\section{DISCUSSION}

The results indicate that, starch extracts from cassava and sweet potato contained the highest amount of pure starch. This result is attributable to the characteristic 


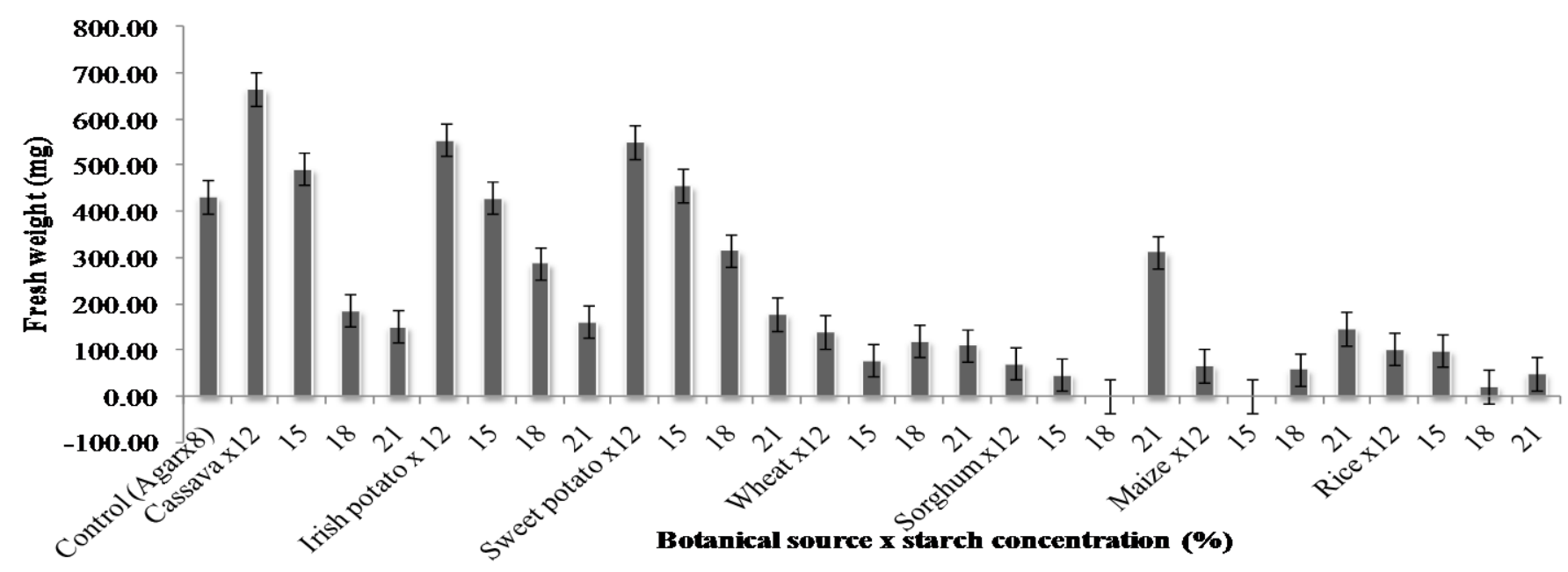

Figure 8. Influence of botanical source of starch and concentration on fresh weight of in vitro plantlets; Means represented with none overlapping standard error bars are significantly different $(p=0.05)$.

behavior of root crops of accumulating large amount of starch in roots and small amounts of other components as was also reported by many authors (Charles et al., 2005; Zaidul et al., 2007). The findings of cassava and sweet potato are consistent with other researchers (Chen et al., 2003; Hoover, 2001; Jangchud et al., 2003). Although the amount of pure starch in extracts from cereals was lower than those in root crops, these results are within established ranges (Kouakou et al., 2008) for the same cereals but different genotypes. These observations in cereal extracts can be associated the genetic tendency of many cereals to accumulate larger amounts of non starch biopolymers such as protein, fats and other organic acids which are usually tightly entangled in grain endosperms than it is in root crops (Kouakou et al., 2008) observed in maize, rice, millet and wheat. Large amount of protein and fat of cereal grains is accumulated in the germ parts as food for the growing embryo during seed germination.

The observed differences in amylose contents between starch extracts may be due to genetic differences between botanical types. This is because the variation between and within species in terms of amylose content is genetically controlled and is a trait with high heritability (Mishra and Rai, 2006). High amylose contents in cereal starch extracts and low levels in root and tuber crops is reported for the same species but different cultivars (Nuwamanya et al., 2010; Oludare and Macdonald, 2010). Due to the direct influence of amylose content on properties of starch gel and that it has a negative correlation with gel strength (Sumnu, 2001), it can be predicted that, starch extracts with low amylose content may form stable semisolid TC media at a lower concentration than those with high amylose content. In this case therefore high amylose starch extracts like those from rice and sorghum will require large amount of starch powder to form a standard semisolid TC media.

Differences in swelling power between starch extracts may be attributed to amylose content, granular structure and amounts of non starch biopolymers of each starch extract. The low swelling power observed on some of the cereal starches may be a result of the extensive and strongly bond micellular structure which makes them relatively resistant to swelling (Nuwamanya, et al., 2010). High swelling power in starch extracts with low amylose content such as cassava, sweet potato and wheat is expected because, as the starch granules absorb water the amylose reinforces the internal network within the granules thus restricting swelling of starch with high amylose content compared to those with small amounts of amylase (Riley et al., 2006).

Furthermore, the low swelling power of starch extracts of Irish potato, rice, maize and sorghum can be associated to low starch purity as was observed in Table 1. This is because starch extracts with large amounts of non starch biopolymers like lipids seem to inhibit swelling of starch granules (Riley et al., 2006). This observation is strongly supported in the previous reports which established that swelling power of many starches are negatively correlated to amylose and lipid contents with correlation coefficients of about -0.84 and -0.68 respectively (Tester et al., 2006; Tester and Karkalas, 1996; Tester et al., 2004). Another reason could be high protein content (Table 1) since the protein molecules have a tendency of interacting with amylose molecules due to opposite charges which form protein-amylose complex hence it restricts swelling (Shimelis et al., 2006).

Swelling power of starches is of great significance in TC media formulations as it enhances movement and availability of water, growth regulators and nutrient solutes to the in vitro plants. The results therefore suggest that the TC media gelled by starches with higher 
swelling power would be expected to release the nutritional ingredient from its matrices at a faster rate than those with low swelling power. Therefore, these results imply that the TC media gelled with wheat, cassava and Sweet potato starches would support in vitro plant growth better than those solidified by rice, maize, sorghum and irish potato.

The results show that, swelling power increased with increasing temperature from 30 to $60^{\circ} \mathrm{C}$. This result can be explained as due to the insoluble starch granules which start to swell during hydration as they begin to integrate with water a molecule which is probably enhanced by increment in incubation temperatures. However within the same change in incubation temperature, wheat, sweet potato and cassava showed higher rate of increasing swelling power than the rest. The low amylose content in cassava and sweet potato is probably due to the longer chains in amylopectin structure which is water loving (Riley et al., 2006). These findings agree with those reported for sweet potato starch (Chen et al., 2003), yam (Diascorea alata L) starch (Riley et al., 2006), common bean (Phaseolus vulgaris L) starch (Shimelis et al., 2006) and cassava and Irish potato starches (Yuan et al., 2007). However the decrease in swelling power of maize starch disagrees with other findings (Fasasi et al., 2007) that the swelling power of both starch and flour from maize increased with increasing temperature.

Compared to root crop (cassava and sweet potato) starches, the low pH of cereal starches might be due to the presence of high amounts of non starch impurities which are acidic in nature like amino and fatty acids from protein and fat biopolymers as was noted in Table 1. The normal $\mathrm{pH}$ of TC media for many plant species including sweet potato is usually around 5.7. Therefore the TC media which is solidified by gelling agents like starch from maize, rice, wheat and sorghum with lower $\mathrm{pH}$ than the normal values would need more of base/alkali to adjust the $\mathrm{pH}$ to normal. Similarly, gelling agents like cassava, sweet potato and irish potato which have $\mathrm{pH}$ that is higher than the normal values would need a lot of acid to neutralize it to normal. Excessive application of acid or base to bring the $\mathrm{pH}$ of TC media to normal has implication on the production cost. Therefore, gelling agents with extremely low or high $\mathrm{pH}$ values may be expensive in terms of acid-base requirements.

The differences between treatments in gel strength are associated with starch purity and amylose contents and this observation is in agreement with many other authors (Blazek and Copeland, 2008; Campo and Tovar, 2008). It has been noted that at the same concentration, starches with high amylose content formed weaker solid gel than those with low amylose content. Due to similar reasons, the results show that at the same concentration of starch, the gel strength of TC medium varied with the botanical sources. As a result therefore, the minimum concentration of starch extract that was required to form a stable semisolid TC medium with gel strength enough to support in vitro plant growth also varied with the source of starch. The stable TC medium was characterized of being semisolid, which adheres well to the bottom of the container (for example, culture bottle) such that it does not become sloppy and flow when the container is tilted. The increase in the amount of any gelling agent in TC media increases the cost of micropropagation, hence low concentration of starchy gelling agent which form TC media with stable gel strength are preferred for cost effectiveness.

Since starch granules are usually white, occurrence of different colours of the starch extracts may a result of presence of non starch impurities such as polyphenols, ascorbic acid and carotene which may have negative effects on the starch quality and the final functionality of starch as reported elsewhere (Shimelis et al., 2006). Reports show that the colour might be affected by the irreversible structural change of the molecular order of the starch granules that occurs after a gelatinization temperature is reached during heat treatment (Sasaki, 2005; Spigno and De Faveri, 2004).

Lack of transparency or clarity of starch gels is attributable to presence of non starch components like protein, lipids and phosphorous which the available findings show that they influence the transparency and clarity of starch gels (Shimelis et al., 2006; Spigno and De Faveri, 2004). Both gel colour and clarity of TC media are important properties in management of in vitro culture especially the identification of contaminated cultures as well as the type of contaminant. This is because exudates of some microbial contaminants have colours similar to the colour of the starch based TC media. In such a situation it may be difficult to note the growth and identify the type of contaminant as early as possible.

The growth of shoots in vitro on agar gelled media outperformed those of starch gelled media except for the number of leaves per shoot which cassava starch media recorded the highest response. Of all the starch gelled media, the best growth response was observed in cassava. In comparison with other starch based media, high numbers of nodes and leaves per shoot, height and fresh weight on cassava starch media may be due to its characteristic low gel strength which probably enhanced the availability of water and nutrients due to low resistance to diffusion and closer contact between the explant and the medium.

Previous reports establish that the better response on cassava starch gelled media could be due to the absence of inhibitors which have been reported to be present in agar (Kuria et al., 2008). The results in this study are in agreement with previous report for cassava flour (Maliro and Lameck, 2004), corn starch (Van et al., 2012) and Irish potato starch (Ibrahim et al., 2005). Other reports show that the good growth responses on root starch (cassava and sweet potato) based media may be due to their tendencies of acting as an additional source of carbon (Onuweme, 1982). Also, they could be source of 
the beneficial nutrients present which acts as ionic supplements (35\% carbohydrates, $1 \%$ mineral matter) to the medium, which may have resulted into improved cell growth and morphogenesis. Although the results was a declining plant performance with increasing concentration of all botanical starches, the improved performance at $15 \%$ cassava starch, $12 \%$ sweetptato and irish potation can be associated with optimal conditions created by the TC media such as good anchorage and free movement of nutritional factors within the media matrix. Low performance of cassava starch in $12 \%$ concentration could be associated with low gel strength leading to inadequate anchorage of explants, keeping explants submerged and photo-chemically inactive. Poor plant growth in concentrations above $18 \%$ can be explained by limited movement of nutrients within media matrix which is also reported elsewhere (Kuria et al., 2008)

\section{Conclusions}

In terms of supporting in vitro plant growth, agar based media are superior to starch based media. However, it was observed that good performance was observed in starch extracts with large amount of total starch, low amylose content and high swelling powers. From these results therefore, starches extracted from cassava, sweet potato and Irish potato have high potential of being alternative gelling agents upon some improvement. Concentration required to create optimal gel strength is high and provide room for improvement. The colour and clarity of starch gels is not favourable in management of cultures.

\section{Conflict of interests}

The authors have not declared any conflict of interests.

\section{ACKNOWLEDGEMENT}

The authors acknowledge the financial support of the BIO-EARN for making this study a success.

\section{REFERENCES}

Agudelo A, Varela P, Sanz T, Fiszman S (2014). Native tapioca starch as a potential thickener for fruit fillings. Evaluation of mixed models containing low-methoxyl pectin. Food Hydrocoll. 35:297-304.

Babbar S, Jain R, Walia N (2005). Guar gum as a gelling agent for plant tissue culture media. In Vitro Cell. Dev. Biol.-Plant 41(3):258-261.

Babbar SB, Jain R (2006). Xanthan gum: an economical partial substitute for agar in microbial culture media. Curr. Microbial. 52(4):287-292.

Benesi IRM (2005). Characterisation of Malawian cassava germplasm for diversity, starch extraction and its native and modified properties. University of the Free State.

Beta T, Corke H (2001). Genetic and environmental variation in sorghum starch properties. J. Cereal Sci. 34(3):261-268.

Bhagya B, Sridhar KR, Seena S, Young C-C, Arun A, Nagaraja K
(2006). Nutritional qualities and in vitro starch digestibility of ripened Canavalia cathartica beans of coastal sand dunes of southern India. Electr. J. Environ. Agric. Food Chem. 5.

Blazek J, Copeland L (2008). Pasting and swelling properties of wheat flour and starch in relation to amylose content. Carbohydr. polym. 71(3):380-387.

Campo L, Tovar C (2008). Influence of the starch content in the viscoelastic properties of surimi gels. J. Food Eng. 84(1):140-147.

Charles AL, Sriroth K, Huang T-C (2005). Proximate composition, mineral contents, hydrogen cyanide and phytic acid of 5 cassava genotypes. Food Chem. 92(4):615-620.

Chen Z, Schols H, Voragen A (2003). Physicochemical properties of starches obtained from three varieties of Chinese sweet potatoes. J. Food Sci. 68(2):431-437.

Escobar R, HERN ANDEZ C, Larrahondo N, Ospina G, Restrepo J, MU NOZ L, Roca W (2006). Tissue culture for farmers: Participatory adaptation of low-input cassava propagation in Colombia. Exp. Agric. 42(01):103-120.

Fasasi O, Adeyemi I, Fagbenro O (2007). Functional and pasting characteristics of fermented maize and Nile tilapia (Oreochromis niloticus) flour diet. Pak. J. Nutr. 6(4): 304-309.

Gangopadhyay G, Roy SK, Mukherjee KK (2009). Plant response to alternative matrices for in vitro root induction. Afr. J. Biotechnol. 8(13):2923-2928.

George EF, Hall MA, De Klerk G-J (2007). Plant propagation by tissue culture: volume 1. the background (Vol. 1): Springer.

George EF, Hall MA, De Klerk G-J (2008). The components of plant tissue culture media II: organic additions, osmotic and pH effects, and support systems Plant propagation by tissue culture, pp. 115-173.

Goel MK, Kukreja AK, Khanuja SPS (2007). Cost-effective Approaches for in vitro mass Propagation of Rauwolfia serpentina Benth. Ex Kurz. Asian J. Plant Sci. 6(6): 957-961.

Henderson W, Kinnersley A (1988). Corn starch as an alternative gelling agent for plant tissue culture. Plant Cell, Tissue Organ Cult. 15(1):17-22.

Hoover R (2001). Composition, molecular structure, and physicochemical properties of tuber and root starches: a review. Carbohydr. Polym. 45(3):253-267.

Ibrahim KM, Kazal MA, Rasheed KI (2005). Alternative gelling agents for potato tissue culture applications. Majalah Al-Istitsmary Al-Zara'y, 3:80-83.

Ivanova M, Van Staden J (2011). Influence of gelling agent and cytokinins on the control of hyperhydricity in Aloe polyphylla. Plant Cell, Tissue and Organ Cult. (PCTOC) 104(1):13-21.

Jain R, Anjaiah V, Babbar S (2005). Guar gum: a cheap substitute for agar in microbial culture media. Lett. Appl. Microbiol. 41(4):345-349.

Jangchud K, Phimolsiripol Y, Haruthaithanasan V (2003). Physicochemical properties of sweet potato flour and starch as affected by blanching and processing. Starch-Stärke, 55(6): 258-264.

Ji Y, Seetharaman K, White P (2004). Optimizing a small-scale cornstarch extraction method for use in the laboratory. Cereal Chem. 81(1):55-58.

Kouakou B, Albarin G, Louise OA, Théodore DND, Youssouf K, Dago G (2008). Assessment of some chemical and nutritional properties of maize, rice and millet grains and their weaning mushes. Pak. J. Nutr. $7(6): 721-725$

Kruger NJ (2009). The Bradford method for protein quantitation. The protein protocols handbook pp. 17-24.

Kuria P, Demo P, Nyende A, Kahangi E (2008). Cassava starch as an alternative cheap gelling agent for the in vitro micro-propagation of potato (Solanum tuberosum L.). Afr. J. Biotechnol. 7(3): 301-307.

Leach HW, McCowen L, Schoch TJ (1959). Structure of the starch granule. I. Swelling and solubility patterns of various starches. Cereal Chem. 36(6): 534-544.

Lee CM, Chung KH (1989). Analysis of surimi gel properties by compression and penetration tests. J. Texture Stud. 20(3): 363-377.

Li J-Y, Yeh A-I (2001). Relationships between thermal, rheological characteristics and swelling power for various starches. J. Food Eng 50(3):141-148.

Lumdubwong N, Seib P (2000). Rice starch isolation by alkaline protease digestion of wet-milled rice flour. J. Cereal Sci. 31(1): 63-74. Maliro MF, Lameck G (2004). Potential of cassava flour as a gelling agent 
in media for plant tissue cultures. Afr. J. Biotechnol. 3(4):244-247.

Marinho-Soriano E, Bourret E (2005). Polysaccharides from the red seaweed Gracilaria dura (Gracilariales, Rhodophyta). Bioresour. Technol. 96(3):379-382.

Mishra S, Rai T (2006). Morphology and functional properties of corn, potato and tapioca starches. Food Hydrocoll. 20(5):557-566.

Mohamed M, Alsadon A, Al Mohaidib M (2010). Corn and potato starch as an agar alternative for Solanum tuberosum micropropagation. Afr. J. Biotechnol. 9(1):012-016.

Murashige T, Skoog F (1962). A revised medium for rapid growth and bio assays with tobacco tissue cultures. Physiologia Plant. 15(3):473497.

Mweta DE, Labuschagne MT, Koen E, Benesi IR, Saka JD (2008). Some properties of starches from cocoyam (Colocasia esculenta) and cassava (Manihot esculenta Crantz.) grown in Malawi. Afr. J. Food Sci. 2(8):102-111.

Nelson DL, Lehninger AL, Cox MM (2008). Lehninger principles of biochemistry: Macmillan.

Novelo-Cen L, Betancur-Ancona D (2005). Chemical and functional properties of Phaseolus lunatus and Manihot esculenta starch blends. Starch-Stärke, 57(9): 431-441.

Nuwamanya E, Baguma Y, Emmambux MN, Rubaihayo P (2010). Crystalline and pasting properties of cassava starch are influenced by its molecular properties.

Oludare AS, Macdonald IO (2010). Variation in the physical, chemical and Physico-functional properties of starches from selected cassava cultivars. NY. Sci. J. pp. 48-53.

Onuweme I (1982). The Tropical Crops. Yams, cassava, sweetpotatoes and cocoyams p. 145.

Ozel CA, Khawar KM, Arslan O (2008). A comparison of the gelling of isubgol, agar and gelrite on in vitro shoot regeneration and rooting of variety Samsun of tobacco (Nicotiana tabacum L.). Scientia Hortic. 117(2):174-181.

Park SH, Bean S, Wilson J, Schober T (2006). Rapid isolation of sorghum and other cereal starches using sonication. Cereal Chem. 83(6): 611-616.

Payne RW (2009). GenStat. Wiley Interdisciplinary Reviews: Comput. Stat. 1(2): 255-258.

Prakash S (1993). Production of ginger and turmeric through tissue culture methods and investigations into making tissue culture propagation less expensive. Ph. D. Thesis. Bangalore Univ. Bangalore.
Riley C, Wheatley A, Asemota $\mathrm{H}$ (2006). Isolation and characterization of starches from eight Dioscorea alata cultivars grown in Jamaica. Afr. J. Biotechnol. 5(17):1528-1536.

Sasaki T (2005). Effect of wheat starch characteristics on the gelatinization, retrogradation, and gelation properties. Japn. Agric. Res. Quart. 39(4):253.

Shimelis EA, Meaza M, Rakshit S (2006). Physico-chemical properties, pasting behavior and functional characteristics of flours and starches from improved bean (Phaseolus vulgaris L.) varieties grown in East Africa.

Spigno G, De Faveri DM (2004). Gelatinization kinetics of rice starch studied by non-isothermal calorimetric technique: influence of extraction method, water concentration and heating rate. J. Food Eng. 62(4):337-344.

Sumnu G (2001). A review on microwave baking of foods. Int. J. Food Sci. Technol. 36(2):117-127.

Tester R, Qi X, Karkalas J (2006). Hydrolysis of native starches with amylases. Animal Feed Sci. Technol. 130(1):39-54.

Tester RF, Karkalas J (1996). Swelling and gelatinization of oat starches. Cereal Chem. 73(2):271-277.

Tester RF, Karkalas J, Qi X (2004). Starch-composition, fine structure and architecture. J. Cereal Sci. 39(2):151-165.

Van P, Teixeira Da Silva JA, Ham L, Tanaka M (2012). How Does Choice of Substrate and Culture Conditions Affect the Growth and Development of Cymbidium cv. Green Planet'Energy Star'Protocormlike Bodies? Eur. J. Horticult. Sci. 77(5):219.

Vaz-Pires P, Seixas P, Mota M, Lapa-Guimarães J, Pickova J, Lindo A, Silva T (2008). Sensory, microbiological, physical and chemical properties of cuttlefish (Sepia officinalis) and broadtail shortfin squid (Illex coindetii) stored in ice. LWT-Food Sci. Technol. 41(9):16551664.

Villanueva R, Sousa A, Gonçalves M, Nilsson M, Hilliou L (2010). Production and properties of agar from the invasive marine alga, Gracilaria vermiculophylla (Gracilariales, Rhodophyta). J. Appl. Phycol. 22(2):211-220.

Yuan Y, Zhang L, Dai Y, Yu J (2007). Physicochemical properties of starch obtained from Dioscorea nipponica Makino comparison with other tuber starches. J. Food Eng. 82(4):436-442.

Zaidul I, Norulaini N, Omar A, Yamauchi H, Noda T (2007). RVA analysis of mixtures of wheat flour and potato, sweet potato, yam, and cassava starches. Carbohydrate Polym. 69(4):784-791. 